\title{
ANALISIS KETAHANAN BEBAN DINAMIS MATERIAL TURBIN ANGIN TERHADAP KECEPATAN PUTAR ROTOR (RPM) MENGGUNAKAN METODE ELEMEN HINGGA
}

\author{
Lasinta Ari Nendra Wibawa \\ Balai Uji Teknologi dan Pengamatan Antariksa dan Atmosfer \\ Lembaga Penerbangan dan Antariksa Nasional (LAPAN) \\ Email: lasinta.ari@lapan.go.id \\ Dwi Aries Himawanto \\ Program Studi Magister Teknik Mesin \\ Universitas Sebelas Maret \\ Email: dwiarieshimawanto@gmail.com
}

\begin{abstract}
ABSTRAK
Penelitian ini mengkaji tentang ketahanan beban dinamis material CFRP dan Aluminium 6061 untuk material turbin angin terhadap kecepatan putar rotor (rpm). Desain 3 (tiga) bilah turbin angin menggunakan airfoil NACA 2415 dengan panjang $500 \mathrm{~mm}$. Analisis dilakukan secara numerik dengan menggunakan software Autodesk Inventor Professional 2017. Variasi kecepatan rotor yang digunakan yaitu $100 \mathrm{rpm}, 200 \mathrm{rpm}, 300 \mathrm{rpm}$, dan $400 \mathrm{rpm}$. Hasil penelitian menunjukkan material CFRP memiliki faktor keamanan yang lebih baik daripada material Aluminium 6061 saat pengujian dengan menggunakan kecepatan rotor $400 \mathrm{rpm}$.
\end{abstract}

Kata kunci: turbin angin, naca 2415; metode elemen hingga; carbon fiber reinforced polymer (cfrp); aluminium 6061; rpm.

\begin{abstract}
This study examined the dynamic load resistance of CFRP and Aluminum 6061 materials for wind turbine material to rotor speed (rpm). Design 3 (three) wind turbine blades using NACA 2415 airfoil with length of $500 \mathrm{~mm}$. The analysis is done numerically using Autodesk Inventor Professional 2017 software. Variations in rotor speed used are $100 \mathrm{rpm}, 200 \mathrm{rpm}, 300 \mathrm{rpm}$, and $400 \mathrm{rpm}$. The results showed that the CFRP material had a better safety factor than the Aluminum 6061 material when testing using 400 rpm rotor speed.
\end{abstract}

Keywords: wind turbine; naca 2415; finite element method; carbon fiber reinforced polymer (cfrp); aluminum 6061; rpm.

\section{PENDAHULUAN}

Kebutuhan energi dari tahun ke tahun terus meningkat. Hal ini mendorong berbagai pihak untuk meneliti energi alternatif. Salah satu energi alternatif yang tengah diteliti dan dikembangkan saat ini yaitu energi angin. Energi angin memiliki beberapa kelebihan dibandingkan energi alternatif yang lain. Beberapa kelebihan energi angin adalah teknologinya cukup sederhana, tidak menimbulkan emisi, dan dapat dilakukan di berbagai tempat dengan ketersediaan angin yang melimpah.

Kapasitas terpasang Pembangkit Listrik Tenaga Angin/Bayu (PLTB) pada tahun 2016 hanya mencapai sekitar 1,12 MW (1). Kondisi ini terlihat sangat ironis mengingat potensi energi angin di Indonesia yang dapat dikembangkan mencapai 1,6 GW. Jika dibandingkan dengan kapasitas PLTU yang mencapai 29.880,23 MW, kapasitas PLTB hanya mencapai 0,0037 persen dari total kapasitas PLTU. Hal ini seharusnya menjadi perhatian serius mengingat PLTU sangat tergantung pada ketersediaan bahan bakar fosil khususnya batubara untuk proses pembangkitnya.

Turbin angin merupakan media utama yang digunakan untuk mengubah energi angin menjadi energi listrik. Desain turbin angin yang baik sangat menentukan kinerja dari pembangkit listrik tenaga bayu (PLTB). Struktur turbin angin yang baik harus mampu menahan beban dinamis yang ditimbulkan oleh perubahan lingkungan di sekitar lokasi penempatan turbin.

Beban dinamis adalah beban yang dapat terjadi atau bekerja secara tiba-tiba pada sebuah struktur. Beban dinamis umumnya kecil tetapi berubah-ubah terhadap waktu. Beban dinamis dapat berupa beban 
angin, beban seismik, beban fatigue, dan frekuensi natural. Faktor kemanan untuk suatu struktur mampu menahan beban dinamis yaitu 2-3 (2).

\section{METODOLOGI PENELITIAN}

Penelitian ini menggunakan perangkat lunak (software) Autodesk Inventor Professional 2017 untuk membuat gambar 3 Dimensi (3D) dan melakukan pengujian analisis tegangan (stress analysis) dari baling-baling Turbin Angin.

Autodesk Inventor merupakan perangkat pemodelan parametrik 3D. Parametrik mengacu pada penggunaan parameter desain untuk membangun dan mengendalikan model 3D yang dibuat. Dengan kata lain, untuk memulai sebuah desain terlebih dahulu harus membuat sketsa dasar untuk menentukan profil dari part. Dimensi digunakan sebagai parameter untuk mengatur panjang dan lebar. Parameter dimensi memungkinkan untuk menyusun sketsa dengan masukan yang tepat. Hal ini sangat memudahkan kita saat sedang mendesain suatu produk atau rancangan (3).

Analisis elemen hingga adalah teknik numerik matematis untuk menghitung kekuatan dan perilaku struktur teknik. Secara prinsip, analisis elemen hingga adalah analisis dari obyek kompleks yang dipecahkan dengan membagi obyek menjadi jala (mesh) elemen yang lebih kecil sehingga kalkulasi dapat diatur dan dijalankan. Analisis tegangan yang dilakukan oleh Autodesk Inventor menggunakan metode ini untuk memungkinkan kita menganalisis desain yang sesuai dengan keinginan kita (4).

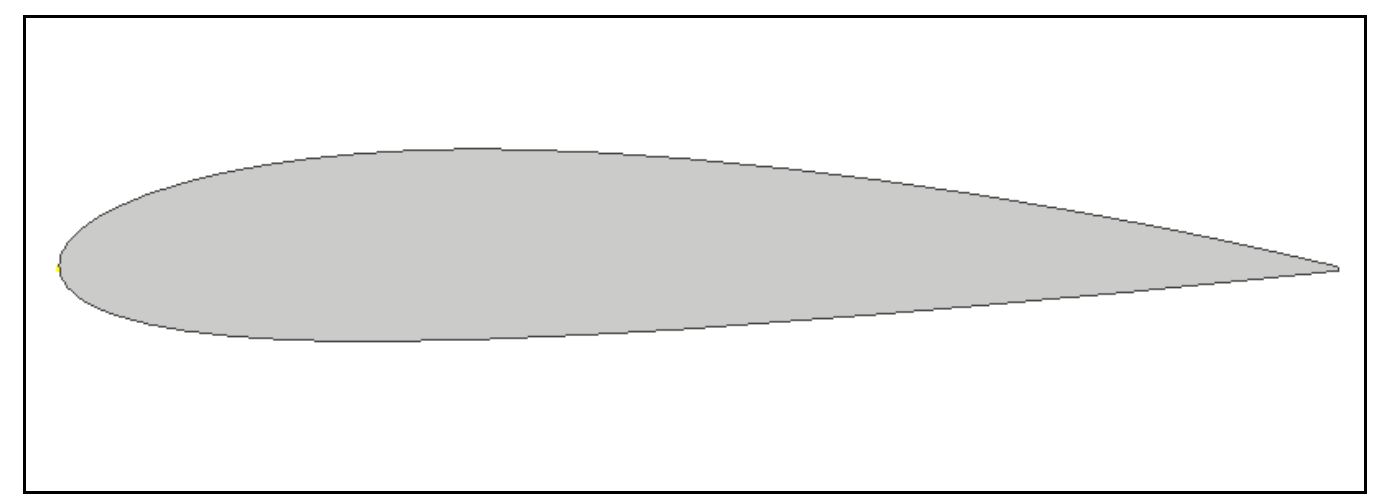

Gambar 1. Profil Airfoil NACA 2415

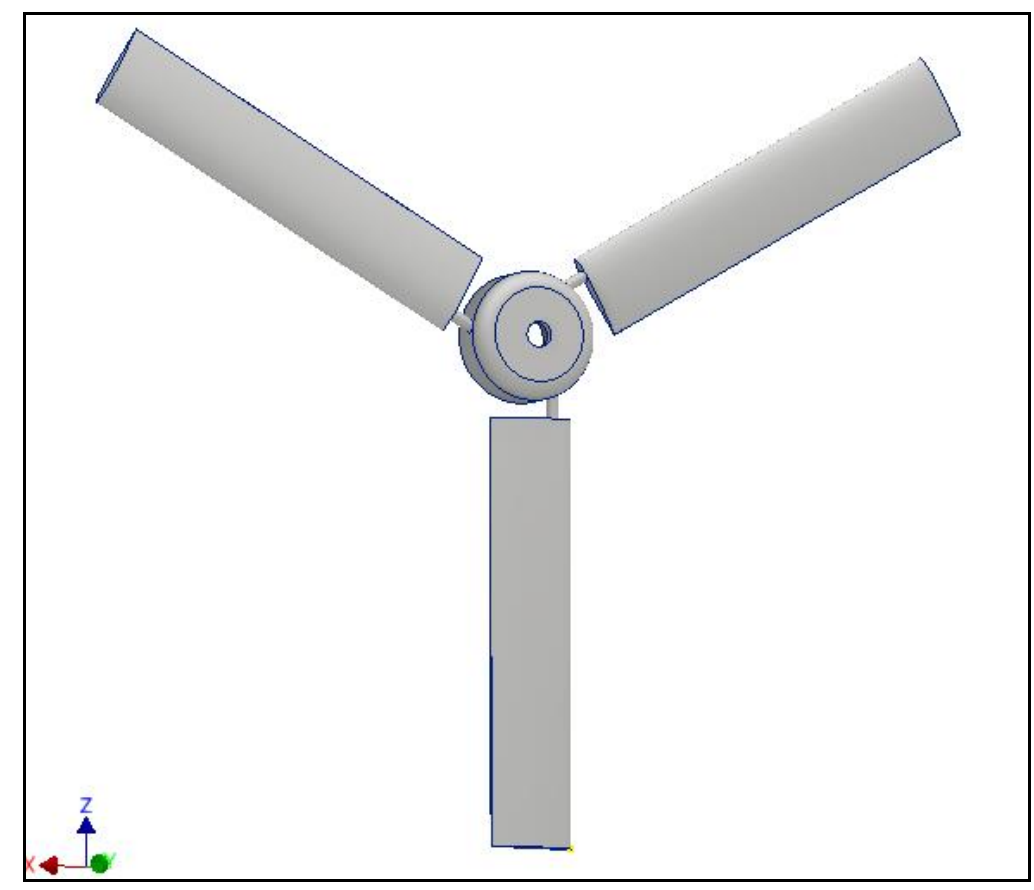

Gambar 2. Desain 3D baling-baling Turbin Angin 
Jenis baling-baling yang digunakan adalah horizontal axis wind turbin blade dengan Airfoil NACA 2415 sebanyak 3 bilah (blade) dengan panjang tiap bilah yaitu $500 \mathrm{~mm}$ (5). Material yang digunakan untuk simulasi yaitu Aluminium 6061 dan Carbon Fiber Reinforced Polymer (CFRP). Variasi dari kecepatan putar rotor yaitu, $100 \mathrm{rpm}, 200 \mathrm{rpm}, 300 \mathrm{rpm}$, dan $400 \mathrm{rpm}$. Parameter Analisis Tegangan dengan menggunakan Autodesk Inventor Professional 2017 secara lengkap dapat dilihat dari Tabel 1 berikut ini.

Tabel 1. Parameter analisis tegangan

\begin{tabular}{ll}
\hline Parameter & Keterangan \\
\hline Tipe Simulasi & Single Point \\
Tipe bilah Turbin Angin & Airfoil NACA 2415 \\
Jumlah bilah & $3 \mathrm{bilah}$ \\
Panjang bilah turbin angin & $500 \mathrm{~mm}$ \\
Average element size & $0,01 \mathrm{~mm}$ \\
Minimum element size & $0,01 \mathrm{~mm}$ \\
Safety Factor & Berdasarkan yield strength \\
Jumlah node & 8811 \\
Jumlah elemen & 4476 \\
\hline
\end{tabular}

\section{HASIL DAN PEMBAHASAN}

\subsection{Analisis Sifat Fisik Material}

Tabel 2 menunjukkan sifat fisik dari material Aluminium Al 6061 dan CFRP. Data menunjukkan bahwa densitas material CFRP sebesar 1,43 gram $/ \mathrm{cm}^{3}$ atau lebih kecil daripada Aluminium yang sebesar 2,7 gram $/ \mathrm{cm}^{3}$. Hal ini berdampak pada massa material CFRP sebesar 3,492 kg, sedangkan Aluminium sebasar $6,593 \mathrm{~kg}$. Hal ini menunjukkan bahwa material CFRP lebih baik ketimbang material Aluminium 6061 karena memiliki massa yang lebih ringan.

Nilai yield strength, ultimate tensile strength, young modulus, poisson ratio, dan shear modulus menunjukkan bahwa material CFRP lebih unggul daripada material Alumnium 6061. Tabel 2 menunjukkan sifat fisik material CFRP dibandingkan dengan material Aluminium 6061.

Tabel 2. Perbandingan sifat fisik material

\begin{tabular}{|c|c|c|}
\hline Material & CFRP & Aluminum 6061 \\
\hline Density & $1,43 \mathrm{~g} / \mathrm{cm}^{3}$ & $2,7 \mathrm{~g} / \mathrm{cm}^{3}$ \\
\hline Mass & $3,4917 \mathrm{~kg}$ & $6,59273 \mathrm{~kg}$ \\
\hline Area & \multirow{5}{*}{\multicolumn{2}{|c|}{$\begin{array}{c}385077 \mathrm{~mm}^{2} \\
2441750 \mathrm{~mm}^{3} \\
x=51,9613 \mathrm{~mm} \\
y=0,920456 \mathrm{~mm} \\
z=595,469 \mathrm{~mm}\end{array}$}} \\
\hline Volume & & \\
\hline Center of Gravity & & \\
\hline & & \\
\hline & & \\
\hline Yield Strength & $300 \mathrm{MPa}$ & $275 \mathrm{MPa}$ \\
\hline Ultimate Tensile Strength & $577 \mathrm{MPa}$ & $310 \mathrm{MPa}$ \\
\hline Young's Modulus & $133 \mathrm{GPa}$ & $68,9 \mathrm{GPa}$ \\
\hline Poisson's Ratio & $0,39 \mathrm{ul}$ & $0,33 \mathrm{ul}$ \\
\hline Shear Modulus & $47,8417 \mathrm{GPa}$ & $25,9023 \mathrm{GPa}$ \\
\hline
\end{tabular}

\subsection{Analisis Tegangan}

Tabel 3, Tabel 4, Tabel 5, dan Tabel 6 menunjukkan analisis tegangan material CFRP dan Aluminium 6061 terhadap variasi kecepatan rotor 100, 200, 300, dan $400 \mathrm{rpm}$. Tabel 3, Tabel, 4 dan Tabel 5 dapat diamati bahwa material CFRP dan Aluminium 6061 cukup aman untuk menahan beban dinamis karena nilai safety factor yang dipersyaratkan material untuk menahan beban dinamis yaitu 2-3.

Tabel 6. menunjukkan bahwa material Aluminium 6061 tidak cukup aman untuk menahan beban dinamis saat kecepatan putaran rotor $400 \mathrm{rpm}$. Hal ini dapat dilihat dari nilai safety factor Aluminium 6061 yang hanya sebesar 1,94. Sedangkan material CFRP cukup aman karena memiliki faktor kemanan sebesar 4,12. 
Tabel 3. Analisis tegangan pada kecepatan putar $100 \mathrm{rpm}$

\begin{tabular}{lllll}
\hline \multirow{2}{*}{ Nama } & \multicolumn{2}{c}{ CFRP } & \multicolumn{2}{c}{ Aluminium 6061 } \\
\cline { 2 - 5 } & \multicolumn{2}{c}{ Minimum } & \multicolumn{1}{c}{ Maksimum } & \multicolumn{1}{c}{ Minimum } \\
\hline Von Mises Stress & $0,000071065 \mathrm{MPa}$ & $4,55497 \mathrm{MPa}$ & $0,00011935 \mathrm{MPa}$ & $8,84435 \mathrm{MPa}$ \\
Displacement & $0 \mathrm{~mm}$ & $0,0540732 \mathrm{~mm}$ & $0 \mathrm{~mm}$ & $0,199982 \mathrm{~mm}$ \\
Safety Factor & $15 \mathrm{ul}$ & $15 \mathrm{ul}$ & $15 \mathrm{ul}$ & $15 \mathrm{ul}$ \\
\hline
\end{tabular}
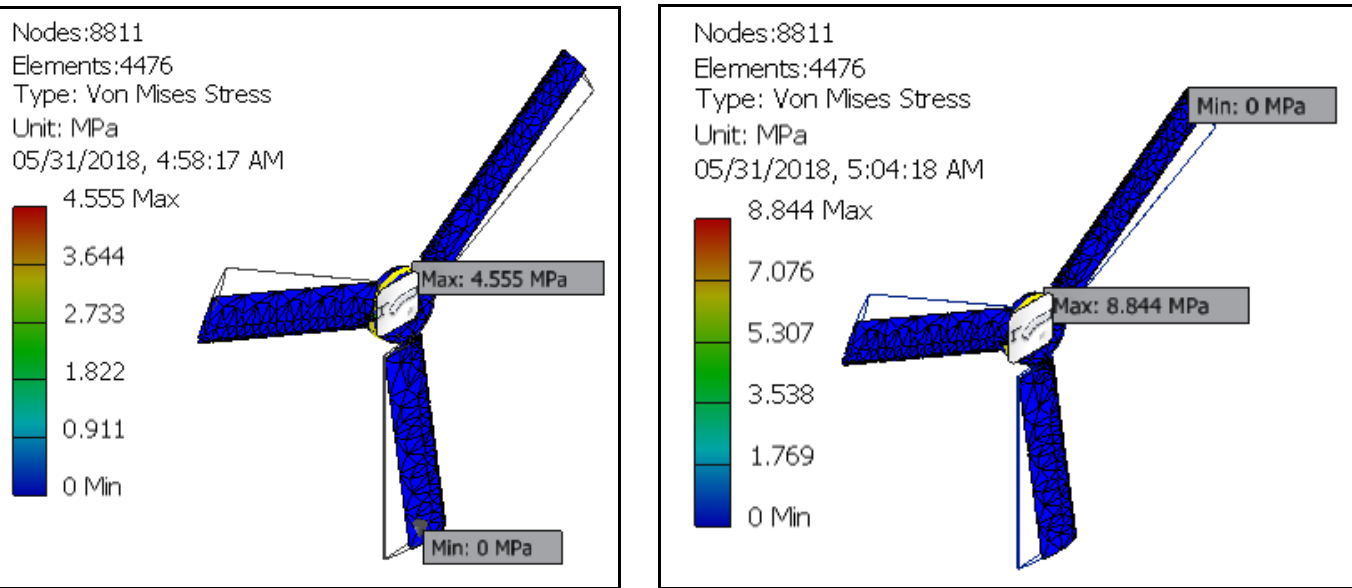

Gambar 3. Tegangan Von Misses Material CFRP (Kiri) dan Aluminium 6061 (Kanan) Pada Putaran 100 rpm

Tabel 4. Analisis tegangan pada kecepatan putar $200 \mathrm{rpm}$

\begin{tabular}{|c|c|c|c|c|}
\hline \multirow{2}{*}{ Nama } & \multicolumn{2}{|c|}{ CFRP } & \multicolumn{2}{|c|}{ Aluminium 6061} \\
\hline & Minimum & Maksimum & Minimum & Maksimum \\
\hline Von Mises Stress & $0,000293813 \mathrm{MPa}$ & $18,2199 \mathrm{MPa}$ & $0,000500913 \mathrm{MPa}$ & $35,3772 \mathrm{MPa}$ \\
\hline Displacement & $0 \mathrm{~mm}$ & $0,216294 \mathrm{~mm}$ & $0 \mathrm{~mm}$ & $0,799923 \mathrm{~mm}$ \\
\hline Safety Factor & $15 \mathrm{ul}$ & $15 \mathrm{ul}$ & $7,77337 \mathrm{ul}$ & $15 \mathrm{ul}$ \\
\hline
\end{tabular}
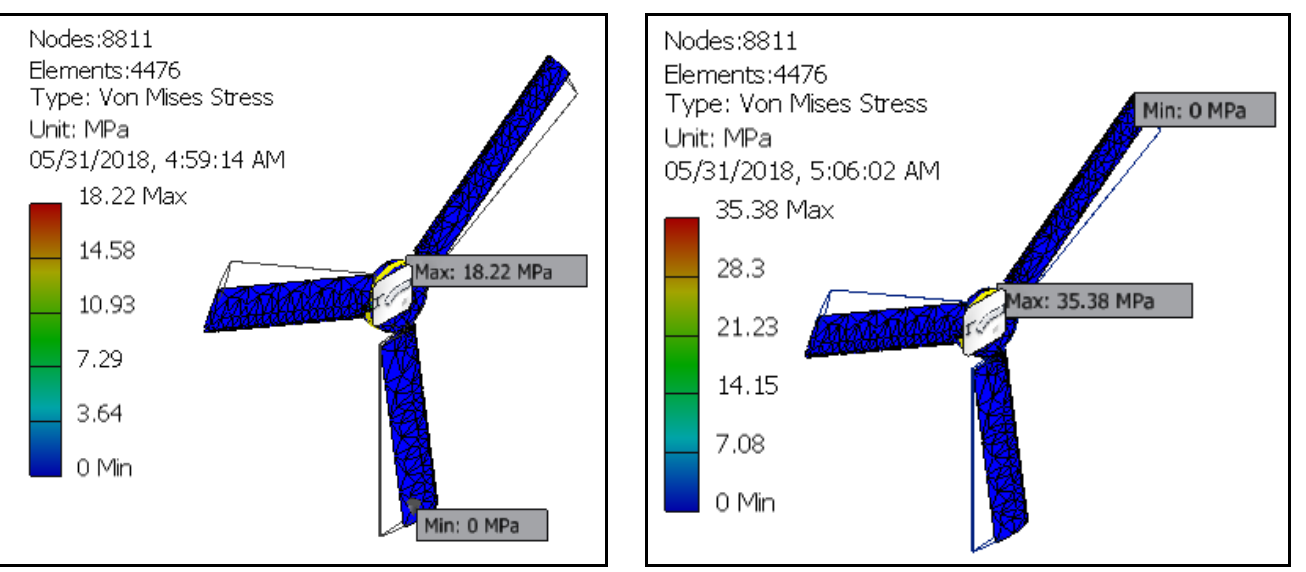

Gambar 4. Tegangan Von Misses Material CFRP (Kiri) dan Aluminium 6061 (Kanan) Pada Putaran 200 rpm 
Tabel 5. Analisis tegangan pada kecepatan putar $300 \mathrm{rpm}$

\begin{tabular}{lllll}
\hline \multirow{2}{*}{ Nama } & \multicolumn{2}{c}{ CFRP } & \multicolumn{2}{c}{ Aluminium 6061 } \\
\cline { 2 - 5 } & \multicolumn{1}{c}{ Minimum } & \multicolumn{1}{c}{ Maksimum } & \multicolumn{1}{c}{ Minimum } & \multicolumn{1}{c}{ Maksimum } \\
\hline Von Mises Stress & $0,000640083 \mathrm{MPa}$ & $40,9949 \mathrm{MPa}$ & $0,0010915 \mathrm{MPa}$ & $79,5973 \mathrm{MPa}$ \\
Displacement & $0 \mathrm{~mm}$ & $0,486661 \mathrm{~mm}$ & $0 \mathrm{~mm}$ & $1,7998 \mathrm{~mm}$ \\
Safety Factor & $7,31798 \mathrm{ul}$ & $15 \mathrm{ul}$ & $3,45489 \mathrm{ul}$ & $15 \mathrm{ul}$ \\
\hline
\end{tabular}
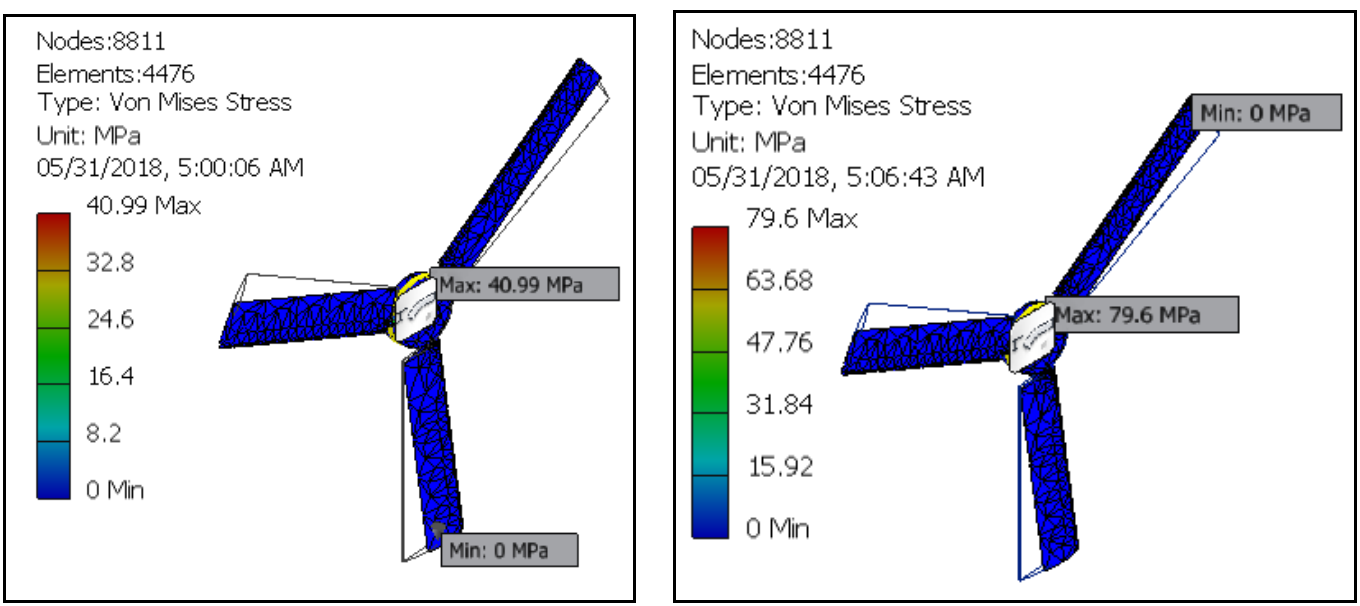

Gambar 5. Tegangan Von Misses material CFRP (Kiri) dan Aluminium 6061 (Kanan) Pada Putaran 300 rpm

Tabel 6. Analisis Tegangan pada kecepatan putar $400 \mathrm{rpm}$

\begin{tabular}{lllll}
\hline \multirow{2}{*}{ Nama } & \multicolumn{2}{c}{ CFRP } & \multicolumn{2}{c}{ Aluminium 6061 } \\
\cline { 2 - 5 } & \multicolumn{1}{c}{ Minimum } & \multicolumn{1}{c}{ Maksimum } & \multicolumn{1}{c}{ Minimum } & \multicolumn{1}{c}{ Maksimum } \\
\hline Von Mises Stress & $0,00113423 \mathrm{MPa}$ & $72,8795 \mathrm{MPa}$ & $0,00197908 \mathrm{MPa}$ & $141,51 \mathrm{MPa}$ \\
Displacement & $0 \mathrm{~mm}$ & $0,86517 \mathrm{~mm}$ & $0 \mathrm{~mm}$ & $3,19967 \mathrm{~mm}$ \\
Safety Factor & $4,11638 \mathrm{ul}$ & $15 \mathrm{ul}$ & $1,94332 \mathrm{ul}$ & $15 \mathrm{ul}$ \\
\hline
\end{tabular}
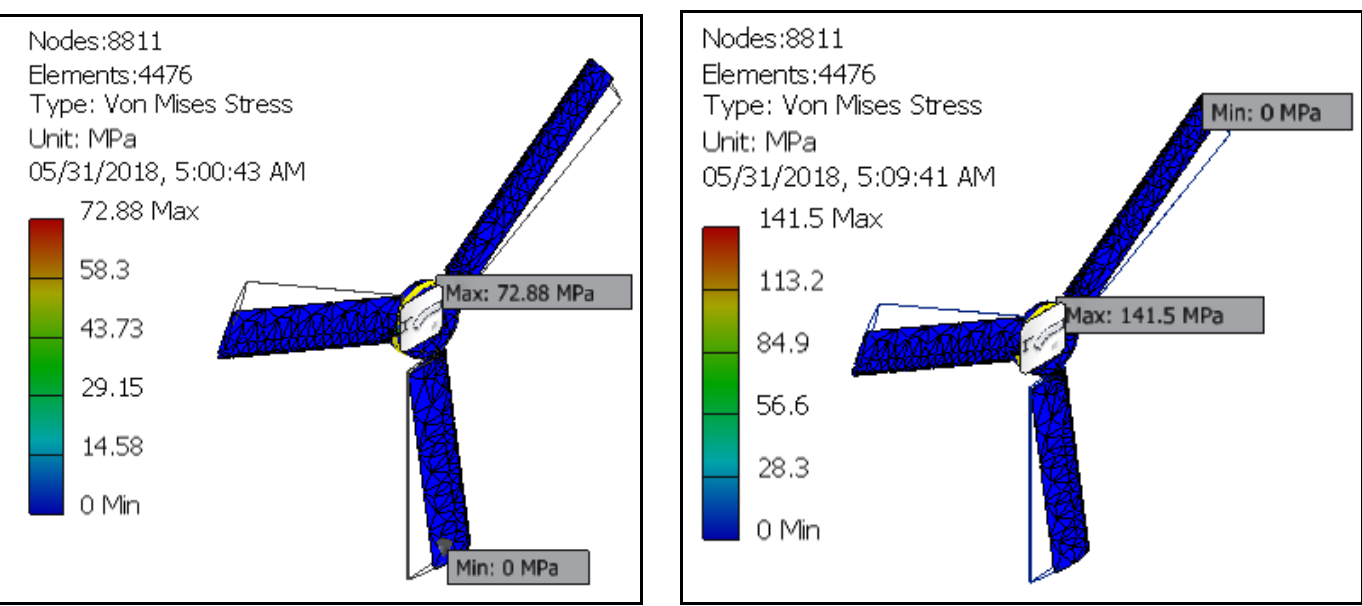

Gambar 6. Tegangan Von Misses Material CFRP (Kiri) dan Aluminium 6061 (Kanan) Pada Putaran 400 rpm 


\section{KESIMPULAN}

a) Desain turbin angin dengan menggunakan material CFRP memiliki massa yang lebih ringan dibandingkan Aluminium 6061. Massa material CFRP sebesar 3,492 kg, sedangkan Aluminium sebesar $6,593 \mathrm{~kg}$.

b) Nilai yield strength, ultimate tensile strength, young modulus, poisson ratio, dan shear modulus material CFRP lebih besar daripada material Alumnium 6061.

c) Pada putaran rotor $400 \mathrm{rpm}$, material CFRP masih memiliki safety factor sebesar 4,12 sehingga cukup aman saat menahan beban dinamis.

d) Pada putaran rotor $400 \mathrm{rpm}$, material CFRP memiliki nilai defleksi yang lebih rendah daripada Aluminium 6061. Defleksi material CFRP sebesar 0,865 mm, sedangkan Aluminium 6061 sebesar 3,199 mm.

\section{DAFTAR PUSTAKA}

[1] Statistik Ketenalistrikan 2016. Direktorat Jenderal Ketenagalistrikan Kemnterian ESDM; 2017.

[2] Dobrovolsky V, Zablonsky K. Machine Elements. Peace Publisher; 1982.

[3] Wibawa, L.A.N. Merancang Komponen Roket 3D dengan Autodesk Inventor Professional 2017. Surakarta: Buku Katta: 2018.

[4] Wibawa, L.A.N. Simulasi Kekuatan Komponen Sarana Pengujian Roket Menggunakan Autodesk Inventor Professional 2017. Surakarta: Buku Katta: 2018.

[5] NACA 2415 (naca2415-il) [Internet]. [cited 2018 Oct 16]. Available from: http://airfoiltools.com/airfoil/details?airfoil=naca2415-il 